\title{
Editorial
}

\section{News on Neuropediatrics}

\author{
Eugen Boltshauser ${ }^{1}$ Bernd A. Neubauer ${ }^{2}$ Barbara Plecko $^{3}$ Graham Brumfield ${ }^{4}$ \\ ${ }^{1}$ Department of Neuropediatrics, Prof. Emeritus, University of Zurich, \\ Zurich, Switzerland \\ 2 Department of Neuropediatrics, University of Giessen, \\ Giessen, Germany \\ ${ }^{3}$ Department of Neuropediatrics, University of Zurich, Zurich, \\ Switzerland \\ ${ }^{4}$ Thieme Publishers, Stuttgart, Germany \\ Neuropediatrics 2014;45:1-2.
}

\section{Dear Colleagues, Dear Readers,}

We would like to update you about several innovations and changes related to Neuropediatrics, which have been effected with the February issue of 2014.

In view of an increasing flow of manuscripts, the page budget of the journal has been increased by more than $10 \%$ in 2014, with a further increase planned for 2015. In addition to the increase in pages, and in order to publish more articles, we are encouraging authors to take advantage of the option to incorporate online-only supplementary material (supplementary figures, tables, references) into their papers. The article categories have been further defined, specifying the allowed word count, number of figures/tables, and number of references. Please consult the modified "instructions for authors" on the journal's Web site.

We continue to encourage authors to submit short communications (case reports), provided they add a relevant and novel aspect to our current knowledge. With this issue, we are opening up the journal to publish supplemental video material. Video material will be accepted along with a paper if it adds substantially to the written message and we will be very selective in this respect. For technical details, please consult the "instructions for authors."

We are pleased to report a constant flow of manuscripts, with a rejection rate in 2012 of just under 50\%. In order to further accelerate editorial process in 2014, we will be asking authors to revise and resubmit manuscripts within 6 weeks of the first decision. Fortunately, we have been able to reverse the declining Impact Factor and saw the journal achieve a score of 1.192 in 2013.

The editorial board too has undergone changes this year. We are grateful to those members who have stepped down and we thank them for their academic contribution to the journal. At the same time, we are happy to welcome our new board members who will feature on the masthead of each issue.

The quality of any journal depends largely on the input from its reviewers. We are very grateful to all reviewers who have supported Neuropediatrics with their expertise. In an effort to thank all reviewers for their invaluable contribution, we will acknowledge them by publishing their names in the first issue of Neuropediatrics each year. For the year 2013, the editors would like to thank the following colleagues (see Thank You, Reviewers!) for their time and expertise in reviewing manuscripts. They not only have enhanced the quality of the content but they also have guided new researchers/authors with their precious advice.

Last but not least, we would like to thank all those who contributed to the successful and timely publication of Neuropediatrics in 2013: authors, reviewers, associate editors, and the publishing team. We are grateful to our readers for their interest, and we continue to welcome feedback.
DOI http://dx.doi.org/ 10.1055/s-0034-1366909. ISSN 0174-304X. 


\begin{tabular}{|c|c|c|}
\hline \multicolumn{3}{|c|}{ Thank You, Reviewers! } \\
\hline Tomoyuki Akiyama & Christoph Helmstaedter & Heike Philippi \\
\hline Filippo Arrigoni & Julia Hennermann & Daniela Pohl \\
\hline Birgit Assmann & Andrew G. Herzog & Andrea Poretti \\
\hline Stephane Auvin & Georg F. Hoffmann & Daniela Prayer \\
\hline Robert Avery & Mitsuaki Hosoya & Susana Quijano-Roy \\
\hline James Barkovich & Thierry Huisman & Karl Reiter \\
\hline Thomas Bast & Peter Huppke & Konrad Rejdak \\
\hline Jan Bauer & Dirk Isbrandt & Harold Rekate \\
\hline Jules G. Becher & Howard Jacobs & Frederik Romi \\
\hline Christoph Berger & Andrew James & Andrea Rossi \\
\hline Roswitha Berger & Mitsuhiro Kato & Kevin Rostásy \\
\hline Steffen Berweck & Toru Kato & Ruth Ruscheweyh \\
\hline Roberta Biancheri & Colin Kennedy & Masayuki Sasaki \\
\hline Michel Billiard & Matthias Kieslich & Ulrike Schara \\
\hline Eugen Boltshauser & Ryutaro Kira & Marina Schoemaker \\
\hline Knut Brockmann & Janbernd Kirschner & Sabine Schollürgi \\
\hline Juergen Brunner & Katrin Klebermass-Schrehof & Peter Schramm \\
\hline Eva Bueltmann & Andrea Klein & Andreas Schulze-Bonhage \\
\hline Pippo Capovilla & Joerg Klepper & Juergen Seeger \\
\hline Anne-Marie Childs & Gerhard Kluger & Alcino Silva \\
\hline Chao Cho-Ming & Alfried Kohlschütter & Deborah Sival \\
\hline Hans-Jürgen Christen & Hirohumi Komaki & Franz Staudt \\
\hline Paul Chumas & Rudolf Korinthenberg & Martin Staudt \\
\hline Alexander Claviez & Barbara Kornek & Maja Steinlin \\
\hline Dana Craiu & Ingeborg Kraegeloh-Mann & Volker Straub \\
\hline Tim de Meij & Günter Krämer & Andreas Straube \\
\hline Marie-Claire de Wit & Sandro Krieg & Jun-ichi Takanashi \\
\hline Tom deKoning & Gerhard Kurlemann & Marc Tardieu \\
\hline Matthew Derrick & Jonathan Kurz & Michael Taylor \\
\hline Olivier Devuyst & Dennis Lal & Carolina Tesi-Rocha \\
\hline Francis di Mario & Mirjam Landgraf & Kathrin Tintelnot \\
\hline Doniel Drazin & Ming Lim & Jun Tohyama \\
\hline Friedrich Ebinger & Doris Lin & Regina Trollmann \\
\hline Harald Erhardt & Rolf Maier & Eberhard Uhl \\
\hline Gareth Evans & Mike Maslin & Enza Valente \\
\hline Martha Feucht & Thomas Mayer & Andreas van Baalen \\
\hline Dirk Fischer & Eugenio Mercuri & Marjo van der Knaap \\
\hline Katsunori Fujii & Sascha Meyer & Conny M. A. van Ravenswaaij-Arts \\
\hline Sabina Gallati & Kenji Mori & Dannis van Vuurden \\
\hline Jutta Gärtner & Wolfgang Mueller-Felber & Adeline Vanderver \\
\hline Elke Gizewski & David Nadal & Clara Vas Marecos \\
\hline Sidney Gospe & Toshisaburo Nagai & Hongyan Wang \\
\hline Michael A. Grotzer & Giancarlo Natalucci & Helene Werner \\
\hline Laurent Guibaud & Richard Newton & Bernd Wilken \\
\hline Adam Hartman & Alex R. Paciorkowski & Michél Willemsen \\
\hline Hans Hartmann & Rainer Pankau & Elaine C. Wirrell \\
\hline Martin Häusler & Jessica Panzer & Nicole Wolf \\
\hline Matthias Heckmann & Zoltan Patay & Ting Zhang \\
\hline Florian Heinen & Aurelia Peraud & \\
\hline
\end{tabular}

